\title{
O HUMOR EM TIRAS EM QUADRINHOS
}

\author{
HUMOR STRIPS
}

\section{EL HUMOR EN CÓMICS}

1 Doutora em Linguística Aplicada e mestre em Linguística pela Universidade Estadual de Campinas (UNICAMP). Atualmente é professora adjunta IV da Universidade Federal de São Carlos (UFSCar). 
RESUMO: Este artigo traz para a reflexão o funcionamento discursivo do humor em tiras em quadrinhos presentes em livros didáticos de inglês como língua estrangeira. O objetivo é compreender o funcionamento discursivo do humor levando em consideração o lugar de sua produção: tiras em quadrinhos. Para isso, apoiamo-nos no aparato teórico da Análise de Discurso de cunho materialista que tem Pêcheux (1988) e Eni Orlandi (1999; 2001) como principais representantes, estabelecendo, ainda, um diálogo profícuo com os estudos freudianos sobre o campo da comicidade.

ABSTRACT: This article brings to the reflection the discursive functioning of humor in comic strips present in textbooks of English as a foreign language. The objective is to understand the discursive functioning of humor taking into consideration the place of its production: comic strips. So, we rely on the theoretical apparatus of Discourse Analysis of a materialistic nature that has Pêcheux (1988) and Eni Orlandi $(1999,2001)$ as main representatives, also establishing a fruitful dialogue with Freudian studies on the comic field.

RESUMEN: Este artículo hace una reflexión sobre el funcionamiento discursivo del humor en cómics presentes en libros de textos de inglés como lengua extranjera. El objetivo es comprender el funcionamiento discursivo del humor teniendo en cuenta el lugar de su producción: tiras cómicas. Para ello, nos apoyamos en el aparato teórico del Análisis de Discurso de naturaleza materialista que tienen Pêcheux (1988) y Eni Orlandi (1999; 2001) como principales representantes, estableciendo, aún, un diálogo provechoso con los estudios freudianos sobre el campo de la comicidad.

PALAVRAS-CHAVE: Análise de Discurso; Humor; tirinhas.

KEYWORDS: Discourse Analysis; Humor; Strips.

PALABRAS CLAVE: Análisis del Discurso; Humor; cómics.

\section{INTRODUÇÃO}

Este artigo traz algumas das reflexóes produzidas na pesquisa que defendemos no Programa de Pós-Graduação Stricto Sensu em Linguística Aplicada do Instituto de Estudos da Linguagem da Universidade Estadual de Campinas (UNICAMP).

O objetivo central do presente trabalho consiste em compreender o funcionamento do humor materializado em tirinhas (quadrinhos de humor) presentes em quatro livros didáticos 
de inglês como língua estrangeira (LE) adotados por escolas públicas da região de Campinas (SP) entre os anos 2005 e 2010.

É comum encontrar em livros didáticos de línguas estrangeiras, especialmente de língua inglesa, uma gama de tipos textuais provindos de diferentes ordens do discurso dentre os quais encontram-se as tirinhas ou quadrinhos de humor (QHs), que estão entre os que mais têm chamado a nossa atenção, por algumas razóes.

A primeira delas diz respeito ao modo de seu funcionamento. Os QHs são um tipo de texto que se caracteriza pelo jogo entre os planos verbal e não verbal, o que rompe com a ideia hegemônica de texto como um conjunto de palavras organizadas. Vale dizer que estamos nos referindo aos QHs constituídos pelo verbal e pelo não verbal conjuntamente, porque há casos de QHs constituídos apenas pelo não verbal. Instigou-nos observar como ambos os planos funcionam produzindo efeitos de sentido.

A segunda razão está relacionada ao funcionamento da comicidade. Sendo uma prática de linguagem, o campo da comicidade - do qual deriva o chiste, o cômico e o humor, conforme a distinção estabelecida por Freud (1989) — manifesta-se majoritariamente na relação conjunta entre a materialidade linguística e imagética. Recorrendo a recursos expressivos constitutivos da própria estrutura significante do sistema linguístico (tais como duplicidade de efeitos discursivos, ironia, ambiguidade, equívoco, trocadilhos, jogos de palavras, entre outros) e do sistema imagético (desenho, caricatura, palavras iconizadas, palavras onomatopaicas), o campo da comicidade atesta o caráter oscilante da língua(gem), desestabilizando-a das estruturações lógico-matemáticas a que ela, muitas vezes, é submetida (FERREIRA, 2000).

Finalmente, a terceira diz respeito ao fato de que o campo da comicidade, do qual fazem parte os QHs, enquanto manifestação estético-artística, está intimamente relacionado ao prazer (à fruição). Ele apresenta, em sua constituição, um funcionamento estético específico, na medida em que trata de questóes existenciais, entre outras, constitutivas da subjetividade, por meio de um modo especial de elaboração dos sentidos. Noutros termos, o 
campo da comicidade traz em seu bojo processos considerados estéticos (EAGLETON, 1993), tais como técnicas e procedimentos iguais ou similares ao funcionamento do inconsciente (condensação e deslocamento, por exemplo), capazes de afetar os sentidos (o corpo) de um modo peculiar. É por isso mesmo, como Freud (1989) bem mostrou, que o humor não é uma "mera brincadeira"; ele implica relaçóes subjetivas, sociais e culturais. Ele é “arma” e defesa da subjetividade ${ }^{2}$.

Por isso, a nosso ver, o campo da comicidade na interface com a arte quadrinizada exerce um papel fundamental na constituição da subjetividade; daí a sua importância no processo de ensino-aprendizagem de uma língua materna e/ou estrangeira ${ }^{3}$.

Por todas essas razóes, acreditamos que os QHs, tipo de texto pertencente ao campo da comicidade, são um material rico tanto para a análise e compreensão de seu processo de significação quanto como objeto de conhecimento no processo de ensino-aprendizagem de uma língua estrangeira. Assim, o presente estudo permitiu-nos compreender os diferentes tipos de comicidade em cada caso, analisando seu funcionamento ao mesmo tempo subjetivo e histórico-cultural.

\section{ArCABOUÇO TEÓRICO-METODOLÓGICO}

\subsection{PRINCÍPIOS E PROCEDIMENTOS DA ANÁLISE DE DISCURSO}

A Análise de Discurso $(\mathrm{AD})$ é considerada uma disciplina do conhecimento científico (ORLANDI, 1999) que teve origem na década de 1960 graças ao filósofo francês Michel Pêcheux. Para instituir-se como uma disciplina do conhecimento, também reconhecida como

\footnotetext{
${ }^{2}$ Ao afirmar isso, não se nega que o humor está relacionado ao lúdico, ao prazer e ao poético; a posição aqui adotada é a de que mesmo esse seu lado não faz dele "mera brincadeira", fruto de uma imaginação ingênua ou de pura descontração sem implicaçóes para a constituição subjetiva dos sujeitos e dos sentidos. Numa abordagem psicanalítico-discursiva do humor, há relaçóes subjetivas, sócio-histórico-ideológicas implicadas na produção do prazer e da poeticidade cômicas, como o trabalho irá mostrar ao longo da reflexão.

${ }^{3}$ Em razão de espaço e foco de trabalho, a questão concernente ao quadrinho de humor no processo de ensinoaprendizagem de uma língua estrangeira não será contemplada neste artigo, já que ela foi discutida em nossa tese de doutoramento (MOTA, 2010).
} 
disciplina do entremeio, a AD estabelece relação com três regiôes do conhecimento científico, a saber: a Linguística, o Materialismo Histórico e a Psicanálise.

O modo como a $\mathrm{AD}$ apoia-se nesses três campos epistemológicos não se dá de forma passiva ou servil. Ao contrário, a $\mathrm{AD}$ estabelece uma relação crítica com cada um deles, ora apropriando-se de certas afirmaçóes, ora questionando aspectos que foram desconsiderados por razões diversas (metodológicas, políticas, ideológicas, etc.).

Em síntese, da Linguística a $\mathrm{AD}$ se interessa pela afirmação de que a língua tem uma ordem própria, uma espessura material específica, afirmação essa que rompe com a tentativa de ver na língua algum traço espiritual e/ou essencial, de transparência e/ou de naturalidade. Dentro dessa lógica de pensamento, o sentido não está aquém/além da língua nem alocado na língua, mas, sim, o sentido se faz no jogo estabelecido entre os signos presentes no sistema língua. Do Materialismo Histórico interessa a noção de história. Esta é pensada como trama de sentidos (filiação) e não como origem ou evolução cronológica de fatos, tal como é fundamentada na epistemologia positivista. Esse sentido de história é fundamental para pensar a língua diferentemente da Linguística estrutural, que a concebe em sua autonomia absoluta. A $\mathrm{AD}$, ao pressupor o legado do Materialismo Histórico, afirma que há, do ponto de vista materialista, um real da história que afeta diretamente a língua. Noutros termos, para a AD, a língua é só relativamente autônoma, pois, para que faça sentido, é preciso que a história intervenha ${ }^{4}$.

No que concerne à Psicanálise, a noção de sujeito comparece como sendo uma das mais profícuas na consideração da análise do funcionamento dos discursos. Como bem afirma Pêcheux (1988), não há discurso sem sujeito nem sujeito sem ideologia.

Além de constituído pela ideologia, o sujeito também é constituído por desejos inconscientes, afirmação esta que remonta a Freud. Noutros termos, o sujeito tem um

\footnotetext{
4 "Relativamente", pois a língua não funciona por si mesma; para produzir sentido é necessária a sua inscrição na história, ou seja, em um contexto sócio-histórico e ideológico.
} 
inconsciente que o torna descentrado (ou seja, não é centro). Assim, é disperso e contraditório, uma vez que, para se constituir, faz-se necessária a presença do Outro. Longe de se tratar de um sujeito senhor de si, controlador dos sentidos que produz, este é concebido como um ser dividido, descentralizado, porque constituído pelo outro/Outro. Tal noção traz para a consideração o fato de que o sujeito não tem controle total do que diz. Parte do que diz não lhe é acessível, ficando ao gosto do inconsciente. Orlandi (1999, p. 34) assevera:

Ao falarmos nos filiamos a redes de sentidos, mas não aprendemos como fazê-lo, ficando ao sabor da ideologia e do inconsciente. Por que somos afetados por certos sentidos e não outros? Fica por conta da história e do acaso, do jogo da língua e do equívoco que constitui nossa relação com eles. Mas certamente o fazemos determinados por nossa relação com a língua e a história, por nossa experiência simbólica e de mundo, através da ideologia.

Como se lê acima, além do inconsciente, há também a presença da ideologia na produção de sentidos e na constituição subjetiva e identitária.

Da perspectiva discursiva, todo discurso é produzido dentro de condições de produção específicas, o que significa que ele não é neutro nem transparente. Discursivamente, texto e discurso caminham juntos. Parte constitutiva do discurso, todo texto, enquanto materialidade simbólica, é provido de sentido, de discursividades das mais distintas possíveis 5 .

Ou seja, um texto não consiste só e unicamente de palavras nem por um número limite delas. Uma palavra pode somente ter estatuto de texto quando revestida de textualidade, isto é, quando sua interpretação derivar de um discurso que a sustenta, que a provê de realidade significativa.

\footnotetext{
5 A título de esclarecimento, materialidade simbólica é tudo aquilo que significa para e por sujeitos historicamente determinados. Enquanto materialidade simbólica, o texto pode ser tanto uma palavra, um conjunto de palavras organizadas, quanto uma imagem ou ambas, palavras e imagens conjuntamente, como é o caso de textos construídos sob o recurso da quadrinizaçáo ou traçados distintos, como é o caso de desenhos (MOTA, 2010).
} 
Na tese de doutoramento de Mota (2010), discutiu-se sobre os modos de constituição do texto construído pelo plano não verbal:

O mesmo acontece com o plano não-verbal. Uma imagem também pode ser considerada texto, por duas razóes. A primeira é o fato de ela ser uma unidade de significação, isto é, ela significa para e por sujeitos historicamente constituídos. A segunda diz respeito ao fato de que, para significar, ela passa (é atravessada) necessariamente pela língua(gem), isto é, pelas discursividades que se constituem na sociedade. No entanto, no imaginário discursivo, tudo funciona como se o texto fosse apenas um conjunto de palavras impressas. Trata-se aí da primazia do verbal sobre o não-verbal, bastante arraigada em nossa cultura e na tradição linguística que tende a reduzir a significação ao linguístico. Conforme Orlandi (1995, p. 35), há um momento na história da reflexão sobre a linguagem em que se reduz a significação ao linguístico, isto é, "ao fato da linguagem definido pela perspectiva da linguística", posição esta que apaga as diferenças entre o verbal e o não-verbal, como se ambos funcionassem indistintamente, ou entâo se submetesse um (o não-verbal) ao outro (verbal). Opor ou hierarquizar os planos (supervalorizando o plano verbal em detrimento do não verbal) resulta na "assepsia do não-verbal, um seu efeito de transparência, pela sua verbalização necessária" (ORLANDI, 1995, p. 36). A autora propóe um deslocamento dessa oposiçáo e coloca o plano do não-verbal no mesmo nível de importância do plano verbal (MOTA, 2010, p. 46-7).

$\mathrm{O}$ analista de discurso, ancorado num dispositivo teórico de interpretação, tem como tarefa expor o olhar leitor à opacidade da linguagem: a ele caberá compreender como os objetos simbólicos (textos, livros, pinturas, filmes etc.) produzem sentidos, mostrando e compreendo a trama de sentidos que trabalha a linguagem - seja verbal, seja não verbal. Compreender o funcionamento ideológico dos diferentes objetos simbólicos que circulam socialmente é uma de suas funçóes.

\subsection{TEXTO E DISCURSO}

No imaginário social, é sabido que o texto é concebido comumente fora das condições de produção nas quais foi produzido. Ou seja, a inscrição de discursividades, no texto, aparece 
negada, como se o sentido surgisse em sua essência e não no jogo com a língua na história para significar. Discursivamente, sabe-se que todo texto é produzido em determinadas condiçóes, além de estar vinculado a uma memória inscrita nele de modo que a sua leitura pode ser uma ou outra, mas não qualquer uma. Trata-se, pois, das determinações históricas nas quais todo texto é constituído.

Além de esquecer o modo como aquele texto foi/é produzido, esquece-se também o modo pelo qual os sentidos funcionam nele. Isto se dá porque o sujeito pragmático, calcado nas emergências de um mundo "semanticamente normal" (PÊECHEUX, 1988), tomado pela(s) evidência(s) dos sentidos, lê um texto como se este significasse por si só, fora de suas condições de produção. Esse modo de funcionamento resulta da necessidade que tem todo sujeito de dominar sua relação com o não sentido — ou com aqueles sentidos com os quais (não) se identifica ideologicamente —, de ter um mundo "semanticamente normal", referindo-nos, uma vez mais, a Pêcheux.

Discursivamente, o texto, longe de ser uma unidade fechada (isto é, uma superfície plana e transparente, um objeto empírico constituído de começo, meio, progressão e fim), é unidade complexa de significação. Complexa porque todo texto é produzido em determinadas condiçóes de produção, estabelecendo relaçóes com outros discursos, outros textos, outros sentidos possíveis. Atesta-se aí o seu caráter heterogêneo. Assim, enquanto materialidade simbólica, todo texto é construído a partir de outros textos, de outros discursos, sempre marcado por sua relação com a exterioridade, que é constitutiva. A partir dessa posição, interessa-nos abordar o texto como um modo de formulação atravessado pelo interdiscurso, isto é, pela memória discursiva (o saber discursivo) que se constitui ao longo da história e produz dizeres para e por sujeitos historicamente constituídos e atravessados pelo inconsciente. Em outras palavras, o texto, enquanto espaço heterogêneo no qual os sujeitos se subjetivam, está, sempre e inevitavelmente, vinculado a um discurso que é, segundo Authier-Revuz (1998), um conjunto de regularidades enunciativas, no qual se manifesta a dispersão do sujeito, que é constitutivamente heterogêneo e cindido. 
A respeito da heterogeneidade que constitui todo e qualquer texto, vale dizer que quando Foucault (1969) afirma que o texto é um espaço de dissensóes múltiplas, ele está se referindo ao fato de todo texto ser heterogêneo em sua constituição, embora ele possa dissimular transparência e homogeneidade por meio de determinadas marcas linguísticas ingenuamente consideradas neutras, transparentes e objetivas, como é o caso do pronome "se" na função de índice de indeterminação do sujeito. Essa visão de imparcialidade é comumente atribuída a determinados textos, provindos de discursividades como a didático-pedagógica e a científica.

\section{ESPECIFICIDADE DO HUMOR}

No senso comum, sabe-se que o humor é concebido como lugar de brincadeira, diversão e entretenimento.

O presente trabalho opõe-se a essa visão por entender que ela é redutora, já que desconsidera as questóes psíquicas, sociais, ideológicas e culturas que atravessam o humor. Para isso, apoiamo-nos nos estudos de Freud (1989), mais exatamente na obra "O chiste e sua relação com o inconsciente", na qual o autor distingue três categorias - humor, cômico e chiste - como elementos constitutivos de um universo complexo de sentidos, denominado “campo da comicidade”. Embora apresentem algumas diferenças, o trio (humor, chiste e cômico) é o lugar no qual se dá a fruição (prazer) do sujeito (FREUD, 1989; KUPERMANN, 2003).

Desse modo, o presente estudo insere-se numa perspectiva que concebe a comicidade como discurso. Como tal, ela não é um objeto "já-dado", mas linguístico e histórico, construção significante de culturas e sociedades específicas. Acrescente-se, o campo da comicidade, longe de ser lugar de divertimento apenas, é “cenário de desejo e de poder" (FREUD, 1989), aliado, como já dissemos, à arte quadrinizada. Para Freud ${ }^{6}$ (1989), portanto,

\footnotetext{
${ }^{6}$ Como o autor oferece uma contribuição original para a compreensão da comicidade, que pode ser articulada a uma abordagem discursiva do cômico, apoiamo-nos bastante em seus estudos para nossas análises.
} 
o humor consiste numa "técnica”. Assim, o que garante humor não é o conteúdo de uma piada ou chiste, mas seu modo de elaboração; o autor compreende a comicidade como um conjunto de processos psíquicos associados à liberação de prazer. Esse prazer, que ajuda a confrontar as pressôes sobre o psiquismo, é vigiado a todo instante pelo pensamento racional e por inibições sociais.

\subsection{O CAMPO DA COMICIDADE: OS CHISTES, O HUMOR E O CÔMICO}

Das três categorias da comicidade distinguidas por Freud (1989) — chiste, cômico e humor — o autor dedica a maior parte de seu estudo à análise do chiste, que é seu objeto central; ainda que não deixe de abordar as outras subclasses.

A categoria do chiste [Witz] inclui as piadas e os jogos verbais que produzem comicidade. Freud nos dá um exemplo bastante emblemático que retirou do livro Estampas de Viagem, do poeta Heinrich Heine. Narrando a ocasião em que esteve com um milionário, o agente de loteria e pedicuro Hirsch-Hyacinth diz: "ele me tratou como a um dos seus, totalmente familionário [Familionär]" (FREUD, 1989, p. 18).

O chiste, nesse caso, apresenta dois conteúdos: um conteúdo manifesto, correspondente à formulação "familionário", condensação das palavras "familiar" [Familiär] e “milionário" [Millionär], e um conteúdo latente, não dito, que, em outro contexto, poderia ser formulado nos seguintes termos: "ele me tratou como a um dos seus, de modo inteiramente familiar, ou seja, como o faz um milionário". Ou ainda: “a condescendência de um homem rico sempre tem algo de incômodo para quem a experimenta” (1989, p. 19). O modo condensado caracteriza a técnica do chiste. Por meio da "fusão" dos fonemas comuns às duas palavras, o locutor constrói uma expressão alusiva e sintética, chistosa. A princípio, "familionário" pode provocar desconcerto, parecendo uma formação lexical defeituosa e enigmática, mas, em seguida, com a "iluminação", isto é, com o entendimento da palavra, produz-se o prazer e o riso como não aconteceria se a formulação fosse outra (1989, p. 14-5). 
Existe uma crítica à forma como o milionário trata os mais pobres, mas o que importa no chiste é a forma condensada pela qual ele a faz, o que lhe dá um caráter transgressivo e cômico.

Para que o chiste seja eficaz, as duas pessoas envolvidas devem se encontrar mais ou menos sob as mesmas inibiçóes ou resistências internas, já que atua no sujeito uma censura em relação à palavra distorcida ou ao disparate. Discursivamente, as duas pessoas mencionadas por Freud não correspondem necessariamente a dois falantes empíricos. Empiricamente, pode haver inclusive mais de um ouvinte; os interlocutores podem estar um frente ao outro; ou, como no caso dos QHs, um deles (o autor) pode nem estar presente.

O chiste tem como origem a palavra disparatada e o cancelamento das inibiçóes a essa palavra. De forma paradoxal, o que chamamos de condições de produção e suas inibições ao mesmo tempo ameaçam e possibilitam o prazer chistoso, que não existiria sem a censura. Além dessa condição básica, o chiste precisa ser dito e reconhecido como tal. Já em seu estado prévio, se o jogo de palavras escapou da vigilância racional, ele requer outra pessoa a quem possa ser comunicado. $\mathrm{O}$ prazer de quem formula só se completa com o riso do ouvinte/leitor para quem o chiste faz sentido. Implicando o outro que goze com ele, essa forma de comicidade é encarada por Freud como a mais social das manifestaçóes do inconsciente.

Já na categoria do cômico intervêm basicamente dois elementos: o ego e o objeto (uma pessoa ou não) em que se descobre a comicidade. Segundo Freud (1989, p. 180):

O cômico se produz em primeiro lugar como um achado não buscado nos vínculos sociais entre os seres humanos. Nós o descobrimos em pessoas, e certamente em seus movimentos, formas, açóes e traços de caráter (...) A descoberta de que se tem o poder de tornar cômico a outro dá acesso a um insuspeito ganho de prazer cômico e dá origem a uma refinada técnica. Também é possível tornar a si mesmo cômico. Os recursos que servem para tornar alguém cômico são, entre outros, a colocaçáo da pessoa objeto em situaçóes cômicas, a imitação, o disfarce, o desmascaramento, a caricatura, a paródia, o travestismo. Como se sabe, estas técnicas podem entrar ao serviço de tendências hostis e agressivas. 
Indagando sobre a natureza dessa forma de comicidade, Freud se pergunta por que rimos do palhaço. Para ele, rimos por causa do seu gasto excessivo de movimentos. Ele observa, porém, que esse tipo de comicidade náo se produz apenas artificialmente, mas no curso da vida cotidiana, de modo não deliberado. Cita como exemplos o excesso de gasto da criança que póe a língua fora da boca quando está aprendendo a escrever e os adultos que nos parecem cômicos por movimentos concomitantes ou por movimentos expressivos exagerados. O prazer aqui é produzido pela superioridade que sentimos em relação ao outro, ao percebermos que seu gasto corporal é maior do que o anímico (ou psíquico), se comparado ao que teríamos para realizar a mesma ação. Porém, se o contrário se dá, isto é, se o gasto psíquico ou corporal da pessoa observada é menor do que o que teríamos para executar a ação, então passamos a admirá-la. O prazer cômico e o efeito que o torna discernível, o riso, surgiriam de uma diferença de gasto sem aplicação, suscetível, pois, de uma descarga de prazer. Nas palavras de Kupermann (2003, p. 40), "no cômico, o prazer deriva de uma economia na despesa com o investimento em alguma representação que se mostra supérflua”.

Neste e em outros procedimentos cômicos, o prazer surge do rebaixamento [Herabsetzung] da pessoa ou situação objeto, em relação à qual o sujeito que produz o cômico sente-se superior. Entretanto, efeitos penosos opóem-se ao cômico, que depende de um estado alegre, facilitador do riso, e da expectativa de que ele se dê. Se houver sentimentos ou interesses intensos envolvidos, como dor e desprazer, ele não poderá se realizar, pois necessita de certa indiferença. Por essa razão, o cômico se aproxima do carnavalesco de que fala Bakhtin, em que boa parte do prazer é obtido por meio do rebaixamento do outro.

Saliba (2002) nos fornece um bom exemplo do cômico. Segundo ele, o cômico nasce de uma percepção do contrário, como na história da velha de Pirandello que, já decrépita, cobre-se de maquiagem, veste-se como uma moça e pinta os cabelos. Ao se perceber que aquela senhora é o oposto do que uma respeitável senhora deveria ser, produz-se o riso, que nasce da ruptura das expectativas, mas, sobretudo, do sentimento de superioridade. A 
percepçáo do contrário, porém, pode transformar-se num "sentimento do contrário" quando aquele que ri procura entender as razóes pelas quais a velha se mascara na ilusão de reconquistar a juventude perdida; nesse passo, a velha da anedota não está mais distante do sujeito que percebe, porque este último pensa que também poderia estar no lugar da velha - seu riso se mistura com a compreensão piedosa e se transforma num sorriso. É aqui que Pirandello começa a diferenciar o cômico do humor, tal como observa Saliba (2002, p. 24). Vale lembrar que esse sentido de cômico vai ao encontro de uma afirmação de Aristóteles (1998), na Poética, de que a comédia pinta os homens piores dos que eles são, colocando em evidência, bem à semelhança de uma lente de aumento, os seus defeitos físicos e morais. Boa parte desses aspectos do universo cômico é produzida sem que necessariamente se utilizem palavras — é a caracterização (pelo traço, como no caso dos QHs, pelo gesto ou pela palavra) que exagera os defeitos do outro, ou que os parodia, tornando-o risível, como na caricatura a seguir:

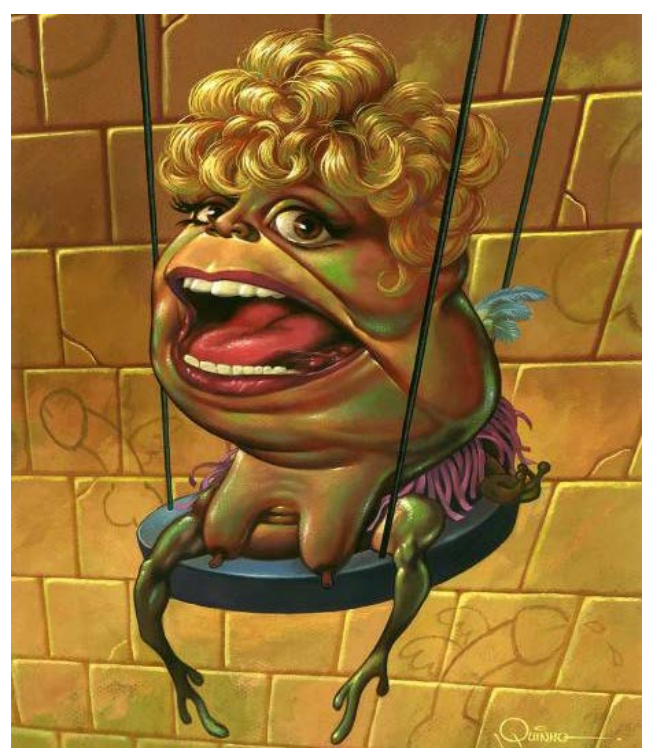

Fonte: (SILVA, 2007, p. 64).

É possível observar que ela também tem aspecto chistoso, pois condensa a imagem da atriz Dercy Gonçalves (que exibia os seios quando velha) e a letra de uma das músicas 
cantadas por ela: "A perereca da vizinha tá presa na gaiola”.

Por fim, a última categoria do campo da comicidade é o humor. Ao contrário do cômico, o humor se caracteriza por surgir diante da adversidade: o prazer humorístico se produz com afetos que normalmente nos seriam penosos. Freud dá como exemplo a frase que o réu condenado à morte na segunda-feira diz a si mesmo a caminho do patíbulo: "Vá, comece bem a semana!". Trata-se de humor de patíbulo ou Galgenhumor, "humor negro". O discurso do réu economiza um afeto doloroso em proveito do prazer humorístico, o que faz com que Freud veja nele um mecanismo defensivo - e de resistência política, diríamos - do sujeito. O humor desestabiliza e desconstrói os sentidos da adversidade (aqui, a própria morte). Conforme Kehl (2002, p. 178), referindo-se a essa mesma história,

[...] o humor aparece revestido de certo heroísmo, caracterizado como coragem de rir, e de fazer rir, diante de circunstâncias que nos parecem trágicas [...] Partindo desse exemplo, Freud aponta o distanciamento entre o comentário e a situaçáo "real" do condenado como fator que produz uma reação de riso, numa situação em que seriam esperadas lágrimas.

Esse heroísmo, essa coragem de fazer rir a que a autora se refere, ao desafiar a morte, triunfa sobre ela. Trata-se de uma tomada de posição: ao invés de se colocar na posição de vítima - que seria o esperado — ou, no dizer de Kehl (2002), "numa situação em que seriam esperadas lágrimas”, o sujeito afronta a morte, atitude dionisíaca por excelência. Nesse sentido, o humor representa o triunfo da subjetividade diante das vicissitudes e dos desastres, correspondendo a uma postura ideológica rebelde, não resignada; é a declaração da invulnerabilidade do sujeito ao mundo. É por conta dessa sua capacidade de rir de si mesmo, "bem distante do "nada me pode acontecer" (KUPERMANN, 2003, p. 123), que Freud (1989, p. 216) considera o humor como a manifestação psíquica mais elevada do campo da comicidade, uma vez que, como declara Kehl (2002, p. 180), “a possibilidade de modificar a relação do homem com seu sofrimento é o que confere ao humor uma dignidade que o chiste, voltado somente para a produção de um efeito prazeroso, não tem”. Mesmo que 
não se expresse num riso franco, como o chiste e o cômico, o humor tem uma dignidade e uma grandeza que faltam a essas formas ${ }^{7}$.

\section{ESPECIFICIDADE DO TEXTO QUADRINIZADO}

Os textos produzidos sob o recurso da quadrinização, também conhecidos como textos de quadrinhos ou textos quadrinizados, são um fenômeno da sociedade midiática, o que significa que eles não podem ser pensados fora dela. Sua configuração é um atestado disso. Mais precisamente, a simplicidade do traço(ado), a linguagem sintética (condensada) e a quantidade de sua tiragem, por exemplo, estão relacionadas às condiçóes de produçáo nas quais este tipo de texto é produzido. Tais características têm íntima relação com a natureza da mídia, da rapidez com que os meios de comunicação de massa precisam ser circulados.

Levando em conta o fato de que cada época produz modos de formulação específicos, podemos dizer que o surgimento da sociedade midiática fez irromper uma diversidade de tipos textuais. Dentre a diversidade de gêneros textuais (midiáticos) que circulam na sociedade, incluindo principalmente a escola, há um tipo de textualização, os quadrinhos, que nos interessa nesta pesquisa.

Os quadrinhos representam, ao modo de um texto, uma unidade de sentido que se oferece à análise. Por isso, é preciso remeter esse tipo de texto ao discurso, entendido como prática histórica dos sentidos. Mais adiante, no último item deste artigo, vamos nos deter na análise de seu funcionamento, mais precisamente no modo como ele significa, expondo sua opacidade ao olhar leitor, parafraseando o francês Michel Pêcheux.

A arte quadrinizada (referimo-nos especialmente às tiras e às histórias em

\footnotetext{
${ }^{7}$ Freud mostra como os diferentes modos de produção da comicidade se estabelecem conforme diferentes relaçôes entre a linguagem, a subjetividade e o contexto social. Suas análises permitem perceber que não se está diante de meras brincadeiras, mas de pontos em que o equívoco e o absurdo representados pelo humor tocam o social e o histórico. O prazer cômico e o riso que o caracteriza não são funcionamentos fisiológicos, mas materialidades discursivas.
} 
quadrinhos) é heterogênea em sua constituição enquanto matéria simbólica. Ela se constitui na articulação com, pelo menos, duas outras artes/linguagens, que também são heterogêneas: a pictórica e a cinematográfica.

As tirinhas, com seu clássico formato de narrativas piadísticas, desdobradas em três tempos ou três quadros, surgem um pouco depois das histórias em quadrinho, ou seja, aquelas são decorrência destas. Entretanto, para o objetivo desta pesquisa, não interessa o estabelecimento rígido das diferenças entre essas duas formas de expressão artística.

Retomando o que dissemos, do ponto de vista do discurso, tirinhas e histórias em quadrinhos são textos, uma vez que estão intimamente relacionadas com a exterioridade, isto é, com o contexto sócio-histórico e ideológico em que são produzidas. Noutras palavras, trata-se de objetos que trazem em seu bojo diferentes gestos de interpretação, diferentes posiçóes do sujeito, diferentes formaçóes discursivas.

A similaridade entre essas duas formas de textualização está no fato de ambas serem um tipo especial de texto caracterizado pelo recurso da quadrinização. O famoso quadrinista Eisner (MENDONÇA, 2002), por exemplo, denomina esse modo de manifestação linguageira como "arte sequencial", devido ao fato de sua estruturação composicional se caracterizar pela justaposição de quadros sequenciais. $\mathrm{O}$ autor utiliza-se da denominação "quadrinhos" para se referir tanto às tirinhas quanto às histórias em quadrinho, que é a mesma posição adotada por nós neste trabalho. Nas palavras de Klawa e Cohen (1972, p. 110),

os quadrinhos, como o próprio nome indica, são um conjunto e uma sequência. $\mathrm{O}$ que faz do bloco de imagens uma série é o fato de que cada quadro ganha sentido depois de visto o anterior; a ação contínua estabelece a ligaçáo entre as diferentes figuras. Existem cortes de tempo e espaço, mas estão ligados a uma rede de açóes lógicas e coerentes.

Com relação ao modo de estruturação (formulação) dos textos quadrinizados, estes são constituídos conjuntamente por narrativa (plano linguístico) e elementos icônicos, tais como a forma e o contorno dos balóes (para a fala, para a expressáo do medo, do sonho, 
do pensamento etc.), o tamanho e o tipo das letras (para sentimentos como a raiva, o grito, o amor etc.), os sinais usados no lugar das letras (para os palavróes, para línguas estrangeiras ou extraterrestres), a disposição do texto (sem parágrafos ou travessóes), por exemplo (MENDONÇA, 2002, p. 206). Esses últimos elementos são fundamentais na constituição do texto quadrinizado e garantem seu reconhecimento, pelo leitor, como um tipo específico.

Tal como observa Bibe-Luyten (1987, p. 12), dentre os diversos elementos que entram na composição dos quadrinhos, os balóes são o que caracteriza a leitura e garante dinamicidade a ela. De acordo com a autora, “o baláo é a marca registrada dos quadrinhos”. Com relação ao seu modo de significação, a autora continua, "na sua forma bemcomportada, [o balão] indica a fala coloquial de seus personagens. No entanto, quando estes mudam de humor, expressando emoçóes diversas (surpresa, ódio, alegria, medo), os balóes acompanham tipologicamente, participando também da imagem”.

De acordo com Bibe-Luyten (1987, p. 18-19), Richard Outcault foi o primeiro quadrinista a introduzir balóes no texto de quadrinhos. Com o seu surgimento, os personagens ganham voz autônoma, resultando no desaparecimento da figura do narrador. Com isso, "a narrativa ganha um novo dinamismo" (BIBE-LUYTEN, 1987, p. 19), pois, além do desaparecimento do narrador, desaparece o texto de rodapé que, inicialmente, acompanhava cada imagem. Resta dizer que, junto com os balóes, surgem as onomatopeias, conferindo efeito de sonoridade às imagens.

No que tange à inserção do plano linguístico no campo imagético dos quadrinhos, Moya (1977, p. 112) afirma que as palavras sofrem um tratamento plástico, passando a ser desenhadas. Nesse sentido, o tamanho, a cor, a forma, a espessura etc. tornam-se elementos importantes para o funcionamento do quadrinizado.

A existência e o funcionamento de quadrinhos nos impóem questionar a clássica definição de texto como mera sequência de parágrafos organizados pelo célebre começo, meio e fim. Os quadrinhos que não apresentam diálogos seriam um exemplo mais nítido disso que estamos afirmando. Podem apenas se constituir de imagens que significam. 
Para terminar a presente seção, vale dizer que os quadrinizados têm íntima relação com o cinema (CIRNE, 2003), não é à toa que eles já foram nomeados de "cineminha de papel" por Mccloud (1995). Dentre as semelhanças significativas entre esses dois processos de manifestação estética (cinema e quadrinho), o autor aponta a decupagem, os cortes, os planos, o enquadramento, o zoom, etc.

Na próxima seção, serão analisados os modos de funcionamento do humor (campo da comicidade), segundo Freud (1989), em tirinhas (quadrinhos).

\section{O HUMOR NO TEXTO QUADRINIZADO}

Embora o campo da comicidade apresente distinçóes (humor, cômico e chiste), não há uma linha rígida separando-as, uma vez que, em grande parte dos QHs, embora haja um desses tipos predominantes, ocorre geralmente uma mescla de processos. $\mathrm{O}$ cômico, por exemplo, sempre se nota no traçado, no desenho. Em nosso corpus, não há textos puramente humorísticos, de um lado, e textos puramente cômicos, de outro, como se houvesse uma fronteira separando-os. Parece haver uma linha tênue atravessando esses processos de significação nos textos. Nesse sentido, há textos que se inscrevem, conjuntamente, nos

domínios do humor e do cômico, sem desconsiderar, ainda, seu caráter chistoso. É o caso da história abaixo: 


\section{Recorte 1: "Hägar e seu cão"}

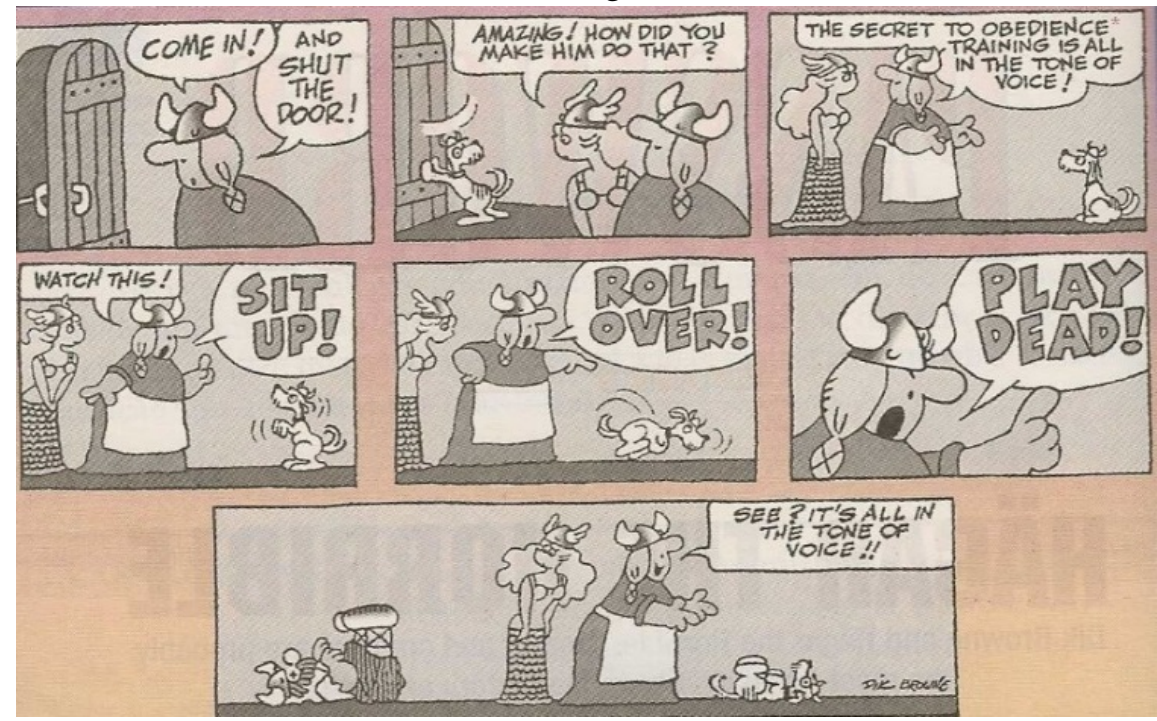

Fonte: (MARQUES, 1999).

O cômico pode ser notado na imagem graças à postura do viking Hägar no último quadro: no chão, fingindo-se de morto como o cachorro à ordem dura da esposa Helga, que diz: "The secret to obedience training is all in the tone of voice!" ${ }^{8}$. O efeito cômico é garantido pelo excesso de gasto inscrito na posição passiva de Hägar, que se submete do mesmo modo que o bicho; é desse rebaixamento e ridicularização do marido que se pode extrair prazer e, consequentemente, o riso.

No recorte 2, a seguir, há um jogo com as diferentes interpretações dos sujeitos, do policial e da senhora, que se fazem de lugares diferentes do discurso:

\footnotetext{
8 “O segredo para o treinamento de obediência está no tom de voz" (tradução nossa).
} 
Recorte 2: "A idosa transgride a lei de trânsito"
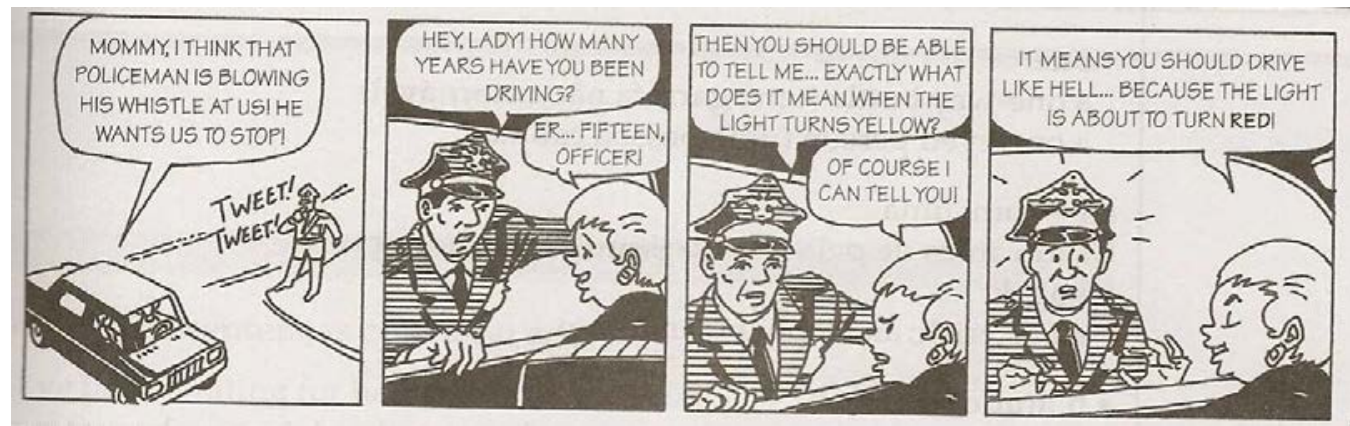

Fonte: (LIBERATO, 2005).

O policial interpreta a partir do lugar da lei; e a mulher, do lugar do infrator. À pergunta do policial "What does it mean when the light turns yellow?" , ela, que passara no sinal amarelo, responde: "It means you should drive like hell...because the light is about to turn red!” ${ }^{10}$. O enunciado da mulher acaba desmascarando ou escancarando o discurso que norteou sua ação, um discurso transgressor. Essa explicitação assume caráter grotesco, isto é, cômico, já que se assume sem vergonha e cinicamente a infração, o que não se espera que alguém diga a uma autoridade de trânsito. A mulher afronta a lei traduzida na figura do policial e, ao fazer isso, surpreende-o (cf. $4^{\mathrm{o}}$ quadro do recorte $)^{11}$. É típico do cômico fazer essa explicitação do considerado socialmente feio, condenável, ridículo, dos chamados vícios: é por meio dela que o cômico desmascara/critica - no caso, o pensamento egoísta e antissocial da mulher que não deseja parar em obediência às leis de trânsito. A surpresa que a resposta produz é materializada no traçado, no desenho. A expressão facial do policial muda drasticamente do $2^{\circ}$ ao $4^{\circ}$ quadro. De feição "rígida" (20 quadro), passa-se a uma feição de surpresa (4º quadro), corroborada conjuntamente por sua expressão facial e traços ao redor de sua cabeça.

\footnotetext{
9 "O que quer dizer quando o sinal fica amarelo?" (tradução nossa).

10 “Quer dizer que você deve dirigir como um louco...porque o farol já vai ficar vermelho!” (tradução nossa).

${ }^{11}$ A reação do guarda, de surpresa, se produz justamente pelo total desprezo da mulher pelo mundo da lei. A legislação de trânsito seria um assunto com o qual não se pode(ria) brincar, mas ela brinca e ri, garantindo o prazer cômico. Em resumo, "leva-se uma multa, mas não se perde a piada”!
} 
O recorte a seguir traz uma réplica chistosa. Observemos:

Recorte 3: "Réplica chistosa do homem franzino"

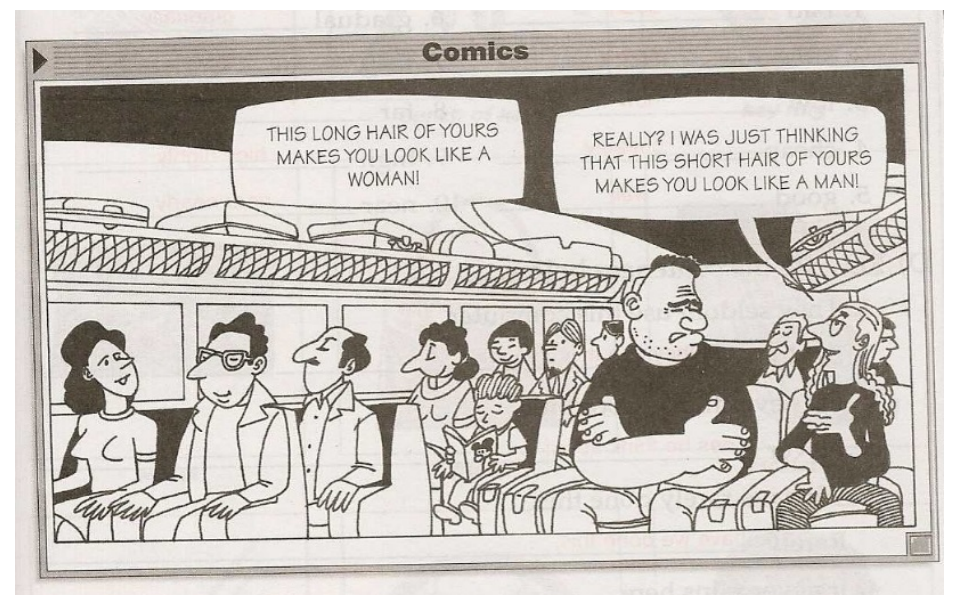

Fonte: (LIBERATO, 1999).

O homem forte e grosseiro, mostrando ar de desprezo em relação ao homem a quem se dirige, de cabelos longos, tipo físico franzino, diz: "This long hair of yours makes you look like a woman!" ${ }^{2}$. A réplica chistosa do homem franzino, "Really? I was just thinking that this short hair of yours makes you look like a man"13, se dá por meio da retomada às palavras do agressor para fazer um sutil contra-ataque ao comentário agressivo; em sua formulação sintética, a réplica questiona diferenças de gênero impostas, socialmente, conforme a aparência física, questionando a obviedade das classificaçóes baseadas em preconceitos, sem fazer um longo e explícito discurso sobre esses preconceitos. A nosso ver, trata-se de um chiste.

No recorte 4 abaixo, vemos um exemplo de comicidade gerada por meio da ousadia:

\footnotetext{
12 "Esse seu cabelo comprido te deixa parecido com uma mulher!" (tradução nossa).

13 "É mesmo? Pois eu estava pensando que esse seu cabelo curto te deixa parecido com um homem!" (tradução nossa).
} 
Recorte 4: "Beware of dog!" 14

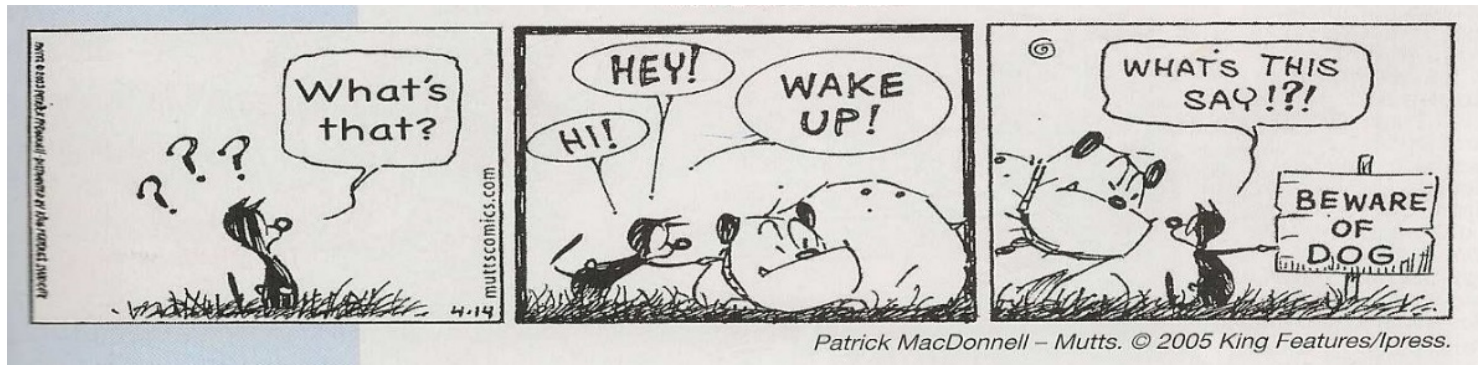

Fonte: (SIQUEIRA, 1997).

A atitude do gatinho de acordar o cão para ler a placa "Beware of dog" 15 , para além de suas intençóes, caracteriza-se como um excesso de ousadia que lembra a de palhaços e outros personagens cômicos — os quais, mesmo diante de grandes perigos, portam-se ingenuamente e provocam potenciais inimigos, ignorando riscos. O efeito cômico é produzido por essa postura desrespeitosa e/ou despreocupada em relação à adversidade, que desconsidera hierarquias e posiçóes opressivas, como, no caso, a do cachorro ameaçador. Com Freud (1989), vimos que o cômico libera da opressão e tira o caráter sublime de personagens elevadas ou sérias. Vale dizer, ainda, que essa postura ousada não é exclusiva dos heróis cômicos, mas também dos criadores do cômico. Afinal, toda criação cômica, por meio da sátira, da caricatura, do rebaixamento, é um gesto de ousadia.

No recorte 5, abaixo, o personagem principal do QH é um cliente irritado com os erros gramaticais presentes num cartaz da cafeteria: "The most gooder coffee who you have ever had" ${ }^{16}$. Observemos:

\footnotetext{
14 "Cuidado com o cão" (tradução nossa).

15 "Cuidado com o cão" (tradução nossa).

16 "O mais melhor café quem você já tomou" (tradução nossa).
} 
Recorte 5: "Paradise coffee"17

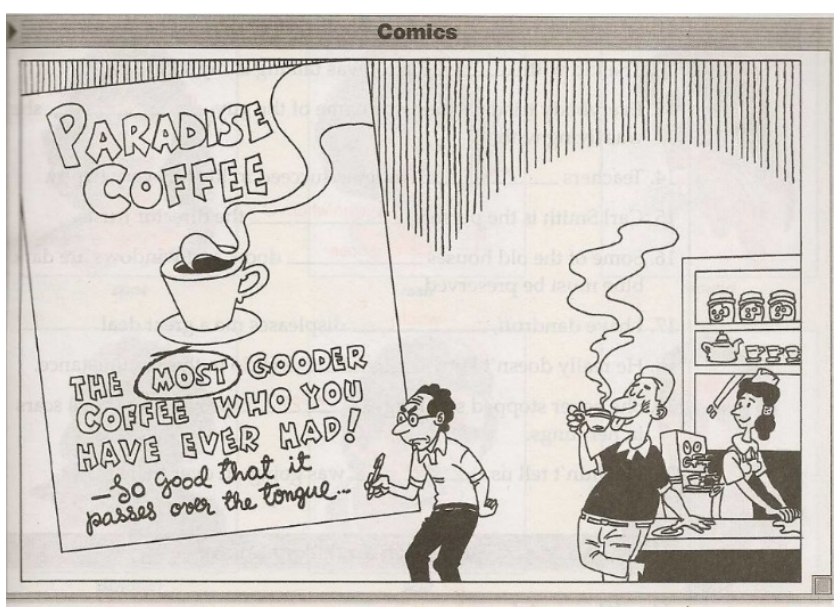

Fonte: (LIBERATO, 1999).

O cliente, com expressão facial raivosa, circula a palavra "most" (mais) e escreve sobre o cartaz o enunciado "So good that it passes over the tongue..." ${ }^{18}$. O "tão bom" da frase do cliente é irônico, sendo denegado pela conclusão que vem na sequência: "que atropela a língua...". Dito de outro modo, o enunciado "so good that it passes over the tongue..." representa uma atitude irônica a despeito do enunciado presente no cartaz (incluídas as reticências). O adjetivo "good" (bom) do enunciado produzido pelo cliente significa o contrário, característica típica da ironia (FREUD, 1989): é denegado pelo que vem depois, qual seja, "pass over the tongue...". Se, de um lado, o homem assume o dizer do cartaz — "um café excelente", "de ótima qualidade" —, de outro, ele desconstrói esse sentido e ridiculariza quem o escreveu. Há um impulso agressivo inscrito nesse enunciado; não raras vezes a comicidade serve à agressão, tal como postula Freud (1989).

Atentemos para o recorte 6 que segue:

17 "Paraíso do café" (tradução nossa).

18 “Tão bom que atropela a língua” (tradução nossa). 
Recorte 6: "The doctor and his pacient" 19

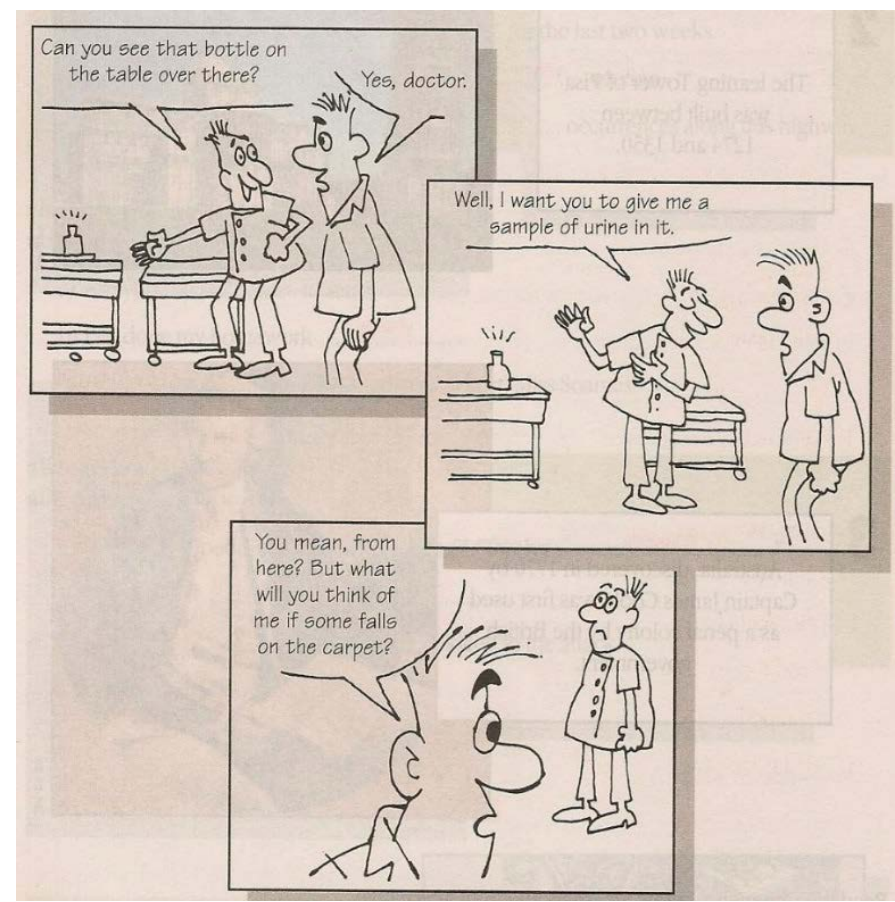

Fonte: (JELIN, 1995).

Nessa história há pontos de equívoco envolvendo os dêiticos "that", "there" e "(from) here" ${ }^{20}$. O médico diz: "Can you see that bottle on the table over there? Well, I want you to give me a sample of urine in it" ${ }^{21}$. O paciente interpreta, entâo, que tem que urinar de onde está para acertar no frasco, dizendo: "You mean, from here? What will you think of me if some falls over the carpet?" 22 . Esse jogo com os dêiticos, a partir do qual a interpretação muda de acordo com cada interlocutor, é tipicamente chistoso e sintético, mas o texto também é cômico: o enunciado do sujeito que vai fazer o exame deixa entrever o enorme gasto que teria para urinar à distância.

No recorte 7 a seguir, também identificamos um aspecto chistoso tecendo a

19 "O médico e seu paciente" (tradução nossa)

${ }^{20}$ Respectivamente: "aquela”, "lá” e "daqui" (tradução nossa).

21 "Está vendo aquele frasco sobre a mesa ali? Bem, quero que você recolha uma amostra de urina nele." (tradução nossa).

22 "Você quer dizer daqui? O que você vai achar de mim se cair um pouco no carpete?" (tradução nossa). 
tirinha:

Recorte 7: "The pop-up book of boxing" 23

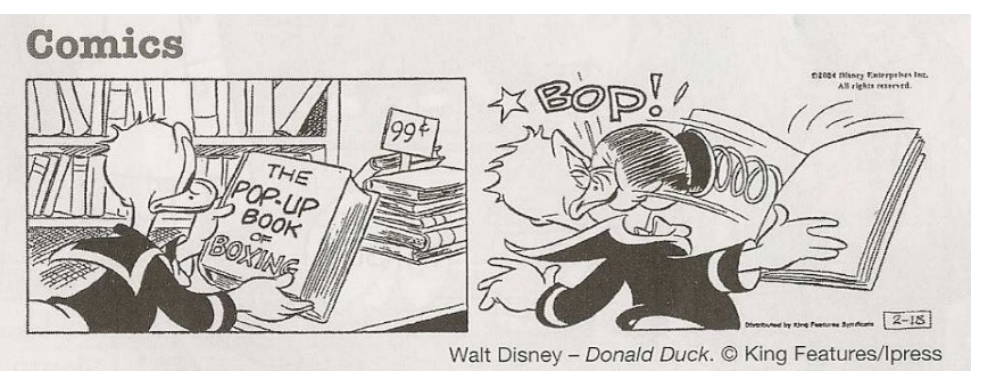

Fonte: (SIQUEIRA, 1997)

Nesta cena, o personagem Pato Donald segura um livro $p o p$ - $и p$ de boxe que traz uma luva de boxe que golpeia quem o abre. Observe-se que o aspecto chistoso se produz no jogo entre o verbal e o não verbal, em que se condensam o título do livro - "The pop-up book of boxing" - e a imagem da luva que dele salta. A luva-surpresa que acerta o leitor é o elemento disparatado, mas que joga com o título (um livro pop-up sobre boxe), produzindo comicidade.

\section{CONSIDERAÇÕES FINAIS}

Em todos os recortes apresentados, a língua comparece como espaço de jogo, dando lugar a deslizes, atestados pela existência da comicidade na interface com a arte quadrinizada. Por meio da materialidade simbólica "tiras em quadrinhos", constituída pelos planos verbal e não verbal, foi possível observar um pouco mais de perto os deslocamentos e efeitos de sentido que, por sua vez, subvertem vários aspectos, como por exemplo: a) o sistema linguístico, surpreendendo sua própria estrutura significante, b) a ideia de que o humor é uma "mera brincadeira" sem maiores consequências para a subjetividade e o psiquismo e, finalmente, c) a ideia de que textos quadrinizados não servem como potenciais objetos de ensino.

23 “O livro pop-up de boxe" (tradução nossa). 
Observou-se que o material apresentado é permeado por vários traços culturais, já que há sempre uma relação necessária da comicidade e da arte quadrinizada com o ambiente sociocultural, como o próprio Freud (1989) já sinalizou. Tal fator pode ser bastante enriquecedor no contexto de ensino de línguas. As questóes culturais mais recorrentes foram: a) o desafio às hierarquias sociais, b) a denúncia e explicitação de transgressóes, vícios e outros aspectos considerados ridículos ou condenáveis social e culturalmente e, finalmente, c) o gosto pela transgressão da lógica como no caso dos chistes. Discursivamente, todos esses elementos consistem num olhar desconstrutor para as realidades sociais, pessoas e lógicas ${ }^{24}$.

Pode-se concluir que a relação entre o campo da comicidade e a arte quadrinizada apresenta um funcionamento bastante peculiar e se revela um lugar profícuo para a produção da leitura tanto no contexto didático-pedagógico de línguas (materna e estrangeira) quanto fora dele. Por isso, acredita-se que compreender essa relação entre comicidade e arte quadrinizada à luz da $\mathrm{AD}$ na interface com os estudos de Freud (1989) tem se mostrado bastante enriquecedor e necessário.

\footnotetext{
${ }^{24}$ Vale dizer que, quando escrevemos "lógica", estamos nos referindo ao logos, à racionalidade, ao "mundo semanticamente normal", sem poesia e humor, e os procedimentos que lhe são comuns. Como foi possível observar, a comicidade materializada no texto quadrinizado rompe com a lógica (leia-se, racionalidade), sobretudo no chiste e no humor. No caso do chiste, Freud fala de "burla da razão"; a razão é a lógica, o logos.
} 


\section{REFERÊNCIAS}

ARISTÓTELES. Poética. Tradução, prefácio e introdução, comentários e apêndices de Eudoro de Souza. 5a . ed. Porto Alegre: Imprensa Nacional, Casa da Moeda, 1998.

AUTHIER-REVUZ, Jacqueline. Palavras incertas: as não coincidências do dizer. Trad. Coord. por Maria Onice Payer. Campinas: Ed. da UNICAMP, 1998.

BIBE-LUYTEN, Sônia Maria. O que é história em quadrinhos. 3a . ed. São Paulo: Brasiliense, 1987.

CIRNE, Moacy Quadrinho, sedução e paixão. Petróplis, RJ: Editora Vozes, 2003.

CORACINI, Maria José Rodrigues. (org.). O jogo discursivo na aula de leitura. Língua materna e língua estrangeira. Campinas: Pontes, 1995.

EAGLETON, Terry. A ideologia da estética. Rio de Janeiro: Jorge Zahar Ed. 1993.

FERREIRA, Maria Cristina Leandro. Da ambiguidade ao equivoco: a resistência da língua nos limites da sintaxe e do discurso. Porto Alegre: Editora da Universidade do Rio Grande do Sul, 2000.

FOUCAUT, Michel. Arqueologia do saber. Petrópolis, Lisboa: Centro do Livro Brasileiro, 1969.

FREUD, Sigmund. (1905). “El Chiste e su Relación con lo Inconciente”. In: Obras Completas, v. 8. 2a ed. Traducción directa del alemán de José L. Etcheverry. Buenos Aires: Amorrortu, 1989.

KEHL, Maria Rita. Sobre Ética e Psicanálise. São Paulo: Companhia das Letras, 2002.

KLAWA, Laonte; COHEN, Haron. "Os quadrinhos e a comunicação de massa”. In: MOYÁ, Álvaro de. Shazam! São Paulo: Editora Perspectiva, 1972, p. 103-14.

KUPERMANN, Daniel. Ousar rir. Humor, criação e psicanálise. Rio de Janeiro: Civilização Brasileira, 2003.

MCCLOUD, Scott. Desvendando os quadrinhos. São Paulo: Makron Books, 1995.

MENDONÇA, Márcia Souza. "Um gênero quadro a quadro: a história em quadrinhos". In: DIONISIO et al. (orgs). Gêneros textuais e ensino. Rio de Janeiro: Lucerna, 2002.

MOTA, Ilka de Oliveira. A comicidade no contexto linguístico escolar: quadrinhos de humor em livros didáticos de inglês como língua estrangeira. 2010. 258 p. Tese (Doutorado em Linguística Aplicada), Instituto de Estudo da Linguagem (IEL), Universidade Estadual de Campinas, Campinas (SP), 2010. 
MOYA, Álvaro. Shazam! São Paulo, SP: Editora Perspectiva, 1977.

ORLANDI, Eni. Discurso e texto: formulação e circulação dos sentidos. Campinas, SP: Pontes, 2001.

ORLANDI, Eni. "Efeitos do verbal sobre o não-verbal". In: Revista Rua, Campinas, n. 1, p. 35-47, 1999.

PÊCHEUX, Michael. Semântica e Discurso: uma crítica à afirmação do óbvio. Campinas: Editora da Unicamp, 1988.

SALIBA, Elias Thome. Raizes do Riso: A representação humoristica na história brasileira da Belle Époque aos primeiros tempos do rádio. São Paulo, SP: Editora Companhia das Letras, 2002.

SILVA, José Ricardo Carvalho. A leitura do gênero tira de humor em uma perspectiva enunciativa. Tese de doutorado. UFF, Niterói, Rio de Janeiro, 2007.

\section{REFERÊNCIAS (LIVROS DIDÁTICOS ANALISADOS)}

JELIN, Israel. English: a high school coursebook. São Paulo: FTD, 1995.

LIBERATO, Wilson. A. Compact English Book: inglês ensino médio. São Paulo: Editora FTD, 1998.

MARQUES, Amadeu. Password: special edition. São Paulo: Editora Ática, 1999.

SIQUEIRA, Rute S. N. Magic Reading, Book 4. 1. ed. São Paulo: Editora Saraiva, 1997. 